Article

\title{
Pressure Applied during Deep Friction Massage: Characterization and Relationship with Time of Onset of Analgesia
}

\author{
Paula Chaves $1, * \mathbb{C}$, Daniela Simões ${ }^{1,2} \mathbb{C}^{-}$, Maria Paço ${ }^{1} \mathbb{C}$, Francisco Pinho ${ }^{1,3}$, \\ José Alberto Duarte ${ }^{4}\left(\mathbb{B}\right.$ and Fernando Ribeiro ${ }^{5}$ (i) \\ 1 CESPU, Institute of Research and Advanced Training in Health Sciences and Technologies, \\ 4585-116 Gandra-Paredes, Portugal; anadanielasimoes@gmail.com (D.S.); maria.paco@ipsn.cespu.pt (M.P.); \\ franciscopinho@gmail.com (F.P.) \\ 2 Santa Maria Health School, 4049-024 Porto, Portugal \\ 3 Applied Artificial Intelligence Laboratory (2AI), IPCA-Instituto Politécnico do Cávado e do Ave, \\ 4750-810 Barcelos, Portugal \\ 4 Research Centre in Physical Activity, Health and Leisure, Faculty of Sport, University of Porto, \\ 4200-450 Porto, Portugal; jarduarte@fade.up.pt \\ 5 Institute of Biomedicine-iBiMED, School of Health Sciences, University of Aveiro, 3810-193 Aveiro, Portugal; \\ Fernando.ribeiro@ua.pt \\ * Correspondence: paula.chaves@ipsn.cespu.pt; Tel.: +351-224-157-100
}

Received: 17 March 2020; Accepted: 10 April 2020; Published: 14 April 2020

check for updates

\begin{abstract}
This study aims to determine if a dose-response relationship exists between the pressure applied during deep friction massage (DFM) and the time to the onset of analgesia in an asymptomatic patellar tendon. For this purpose, pressures applied by physiotherapists during DFM (study 1) were characterized and then, based on these pressures, the effects of different DFM pressures on the time to the onset of analgesia were assessed (study 2). First, the mean pressure applied by 40 physiotherapists during a DFM session was assessed with a pressure sensor through an observational, cross-sectional and analytical study. Next, the effects of different pressure intensities (the median, the percentile 25 (P25), and the percentile 75 (P75) of the mean pressure obtained in study 1) were studied in a crossover trial enrolling 30 participants with an asymptomatic patellar tendon. A pressure sensor was used to register the pressures applied during DFM. Our main results indicated that the physiotherapists applied pressures with a wide variation ((mean pressure: $2.317 \mathrm{~kg} / \mathrm{cm}^{2}$ (P25: $\left.\left.1.022 \mathrm{~kg} / \mathrm{cm}^{2} ; \mathrm{P} 75: 4.161 \mathrm{~kg} / \mathrm{cm}^{2}\right)\right)$. It was also shown that higher pressures had shorter times to the onset of analgesia (pressure: $1 \mathrm{~kg} / \mathrm{m}^{2}$, time to the onset of analgesia: $67.0 \mathrm{~s}$ (P25: $84.5 \mathrm{~s}$; P75: $113.5 \mathrm{~s}$ ); pressure: $2.3 \mathrm{~kg} / \mathrm{m}^{2}$, time to the onset of analgesia: $59.0 \mathrm{~s}$ (P25: $73.5 \mathrm{~s} ;$ P75: $87.3 \mathrm{~s}$ ); pressure: $4.2 \mathrm{~kg} / \mathrm{m}^{2}$, time to the onset of analgesia: $37.8 \mathrm{~s}$ (P25: $54.0 \mathrm{~s}$; P75: $62.0 \mathrm{~s})$ ) ( $p \leq 0.001)$. In conclusion, the mean DFM pressure obtained by the physiotherapists was $2.3 \mathrm{~kg} / \mathrm{cm}^{2}$ (P25: $1.02 \mathrm{~kg} / \mathrm{cm}^{2} ; \mathrm{P} 75: 4.16 \mathrm{~kg} / \mathrm{cm}^{2}$ ). Higher pressures of DFM resulted in shorter times to the onset of analgesia.
\end{abstract}

Keywords: Cyriax; pain; patellar tendon; manual therapy; physical therapists

\section{Introduction}

Deep friction massage (DFM) is a therapeutic resource used in the treatment of tendon injuries based on its potentially positive effects on function and pain [1-10]. When applying DFM, there is a set of basic principles of applications that should be adjusted, depending on the severity or condition of the injury [10]. In addition to the accurate identification of the injured tissue, the physiotherapist should take into account the direction (transversal) and the pressure of the massage ("deep enough") [1]. 
Clinically, its effect on pain is confirmed by the immediate feedback of the patient with tendinopathy, which describes an analgesic effect during and immediately after the application of the technique [10,11]. The positive effects of DFM on pain are often explained by the induction of hyperaemia produced by mechanical stimulus [5,10-13], the modulation of nociceptive impulses at the spinal cord ("gate control theory") [4,5,10,13-15], and also the descending mechanisms of pain modulation [5,10,11,16-19]. Notwithstanding, regardless of the mechanism beyond the analgesic effect of DFM, the mechanical stimulus seems to be a common trigger of this response [16], which in DFM corresponds to the pressure applied during the technique execution.

The principles of the DFM application are quite vague with respect to pressure, once it is described as "deep enough". During DFM, the intensity of the pressure is managed according to the feedback of the patient, and clinically the physiotherapist grades the intensity of the pressure by asking the patient to report whether the pain is bearable $[1,11,12,20,21]$. The pressure aims to guarantee indirect access to the target tissue, which may lead to an alteration of the morphological properties of the tendon and influence pain modulation [11-13,21-24].

It has been suggested that the lack of the standardization of the DFM protocol, namely the pressure applied, could be one of the potential confounding variables concerning DFM's effectiveness [21]. Notwithstanding, taking into account that pain is a symptom used by the physiotherapist as a reference for the management of the pressure applied, the authors question if the standardization claimed for this technique is possible or even useful. Therefore, despite DFM being a widely used technique [10,25-27], there is no study characterizing the pressure applied during DFM, remaining at the discretion of the physiotherapist. Additionally, it is not known how the amount of pressure applied may influence the abovementioned mechanisms and consequently how it affects the time needed to promote an analgesic response. Before further mechanistic or clinical studies are undertaken, it is important to accurately describe the pressure application conditions that elicit an analgesic effect, further enlightening if the standardization of the pressure applied may add clinical value. The purpose of this study was, therefore, to determine if a dose-response relationship existed between the pressure applied during DFM and the time to the onset of analgesia in an asymptomatic patellar tendon. In order to accomplish this, we first characterized the pressure applied during DFM, describing the mean pressure applied by physiotherapists and determining if it was applied uniformly during the DFM execution (study 1). Because pressure may influence the effects of DFM on pain, we further studied the effects of different pressures, based on the mean pressure found in study 1, applied during DFM on the time to the onset of analgesia (study 2).

\section{Materials and Methods}

\subsection{Study Design and Subjects}

The characterization of the pressures applied during DFM (study 1) was determined in an observational, cross-sectional and analytical study enrolling 40 physiotherapists. The recruitment was through direct invitation to physiotherapists that use DFM as a therapeutic resource in the treatment of degenerative tendinopathy. Those with any physical constraint that prevented or restrained the application of the technique or that did not use DFM in the last six months were excluded. The 6-month criterium was applied to ensure the recruitment of those using DFM on a regular basis. Next, after determining the pressures applied by physiotherapists during DFM, the effects of different pressure intensities (the median, the percentile 25 (P25), and the percentile 75 (P75) of the pressures obtained in study 1) on the time to the onset of analgesia were studied in order to ascertain whether a dose-response relationship exists between the pressure and the time to the onset of analgesia (study 2). For this purpose, a randomized, controlled, crossover trial was performed with 30 healthy individuals of both sexes, who were recruited through printed advertisements on notice boards at various sites of our institution. In order to be included, the participants should have had an asymptomatic patellar tendon. Exclusion criteria: the history of previous injury of the lower limbs, the intake of medication 
that could interfere with pain mechanisms, and the presence of any factors or conditions that could interfere with tendinous tissues as well as with the awareness and sensibility to pain or with the neurophysiological response expected.

In both studies, the height and the weight were measured using a stadiometer (Seca ${ }^{\circledR}$, Bodymeter 206, Hamburg, Germany) and a scale, respectively (Tanita BC-545, Tanita ${ }^{\circledR}$, Tokyo, Japan), and the body mass index (BMI) $\left(\mathrm{kg} / \mathrm{m}^{2}\right)$ was calculated. The studies took place at the laboratory of our institution, and data collection occurred during August 2017. Both studies obtained ethical approval by the Ethics Committee of the Faculty of Sports, University of Porto (Process CEFADE 15.2017). All participants provided written informed consent, and all procedures were conducted according to the Declaration of Helsinki.

\subsection{Assessment and Monitoring of the Pressure Intensity during DFM}

In order to quantify the amount of pressure performed by the physiotherapist while executing DFM, an instrument that monitored and recorded the pressure applied was used (Figure 1). This consisted of a piezo-resistive sensor provided by TekscanTM A201 FlexiForceTM (TekscanTM, Inc., South Boston, MA, USA) with an active area of $9.53 \mathrm{~mm}^{2}$ in a pressure range of $0-445 \mathrm{~N}$. The sensor was connected according to the corresponding datasheet specifications to achieve the stated linear error of $3 \%$ at full scale and a repeatability error of $2.5 \%$. To acquire the pressure data, a microcontroller-based platform (Teensy 3.2, PJRCTM, OR, USA) was programmed at a 100 samples per second (sps) sampling frequency. This device ran on a $96 \mathrm{MHz}$ clock with a 16-bit resolution for analog-to-digital conversion. The microcontroller was coupled with a Bluetooth 2.1 + EDR module for wireless data transmission at $230,400 \mathrm{bps}$. Under these specifications, the sensor full-scale bandwidth from 0 to $3.3 \mathrm{~V}$ achieved a resolution of $0.0068 \mathrm{~N}$ (680 micrograms). For data recording and real-time visualization, a WindowsTM (MicrosoftTM, Albuquerque, NM, USA)-based application was used (Figure 1). Before each acquisition, the sensor was properly calibrated with two standard weights. The recorded data were processed under Matlab_R2016a (MathWorksTM, Inc., Natick, MA, USA). Data were first filtered by a low-pass filter with a cut-off frequency of $5 \mathrm{~Hz}$ through a 4th-order Hamming window finite impulse response (FIR).

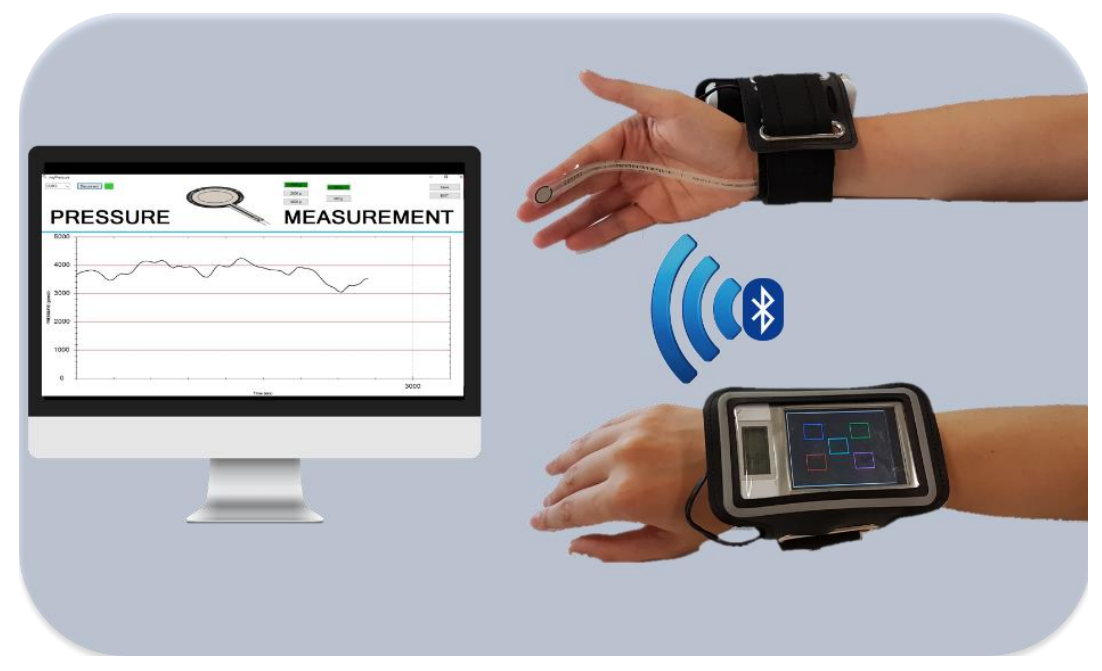

Figure 1. Instrument to monitor and register the pressure.

\subsection{Study 1}

The participants were invited to visit the laboratory of our institution and to perform DFM, as they usually do in their clinical practice (regarding the duration, the pressure, and the positioning of patients and physiotherapists) using the abovementioned instrument. They were allowed to adapt themselves to the instrument before the data collection; all the procedures were supervised by an 
investigator. In order to ensure their blinding concerning the pressure performed, there was no feedback from the instrument. The physiotherapists were instructed to position themselves, adjust the table height, select the hand position and perform DFM according to their usual execution (in real contexts) in one treatment session, including the total time of the DFM application. In order to control any intrinsic variability of the targeted tissue that could influence the intensity of the pressures applied to the participants, DFM was always applied in the same asymptomatic patellar tendon. Furthermore, the position of the subject receiving DFM and the local application of DFM were standardized by positioning the knee with $15^{\circ}$ of flexion controlled by a standard goniometer (Baseline ${ }^{\circledR}$, New York, NY, USA) and setting the application point of DFM at $1 \mathrm{~cm}$ below the inferior border of the patella. After the DFM application, the following pressure variables were extracted: mean pressure, median pressure, minimum and maximum pressures, as well as SD. The total time of the DFM application was measured by the investigator using a chronometer (Nike, Inc., Beaverton, OR, USA).

\subsection{Study 2}

In this study, the instrument previously described was used along with the Windows-based application to allow the physiotherapist to have real-time visualization (feedback) of the pressure applied during DFM. The measured pressure was plotted in real time to give visual and auditory feedback to the physiotherapist applying DFM (Figure 1), hence keeping the pressure constant during all the procedure. The DFM procedure was always performed by the same physiotherapist, which was previously trained in the use of the device. The 30 healthy participants were invited to the lab for three days, $48 \mathrm{~h}$ apart from each other; in each day, the participants received DFM with a different pressure. The three different pressures used in this study were the P25, the median, and the $P 75$ of the pressure registered in study 1 , which corresponded to P1 $=1.0 \mathrm{~kg} / \mathrm{cm}^{2}, P 2=2.3 \mathrm{~kg} / \mathrm{cm}^{2}$, and $\mathrm{P} 3=4.2 \mathrm{~kg} / \mathrm{cm}^{2}$, respectively. The order of application was defined by a simple randomization process (Figure 2), using a random sequence generator (www.random.org). The participants were positioned lying supine, with $15^{\circ}$ of knee flexion controlled by a standard goniometer (Baseline ${ }^{\circledR}$, New York, NY, USA), and the application point of DFM was set at $1 \mathrm{~cm}$ below the inferior border of the patella at the patellar tendon. Taking into account that DFM is performed through a manual pressure that should elicit a bearable pain, the subjects were asked to report analgesia to the investigator, as soon as they stopped feeling discomfort or pain. The time to the onset of analgesia was measured by the investigator using a chronometer (Nike, Inc., Beaverton, OR, USA).

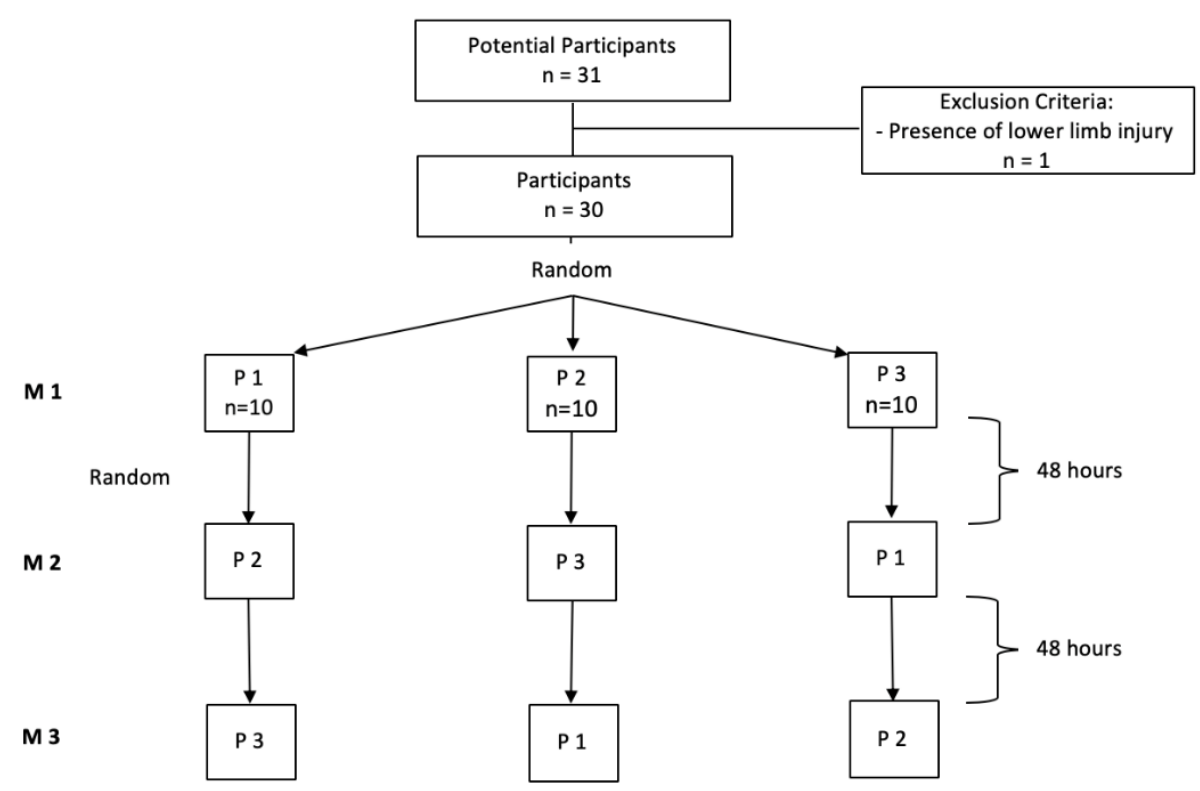

Figure 2. The randomly determined order of the pressure $(\mathrm{P})$ applied in each session/moment (M). 


\subsection{Statistical Analysis}

Descriptive statistics comprised absolute and relative frequencies for categorical variables, and means with SDs or medians with P25 and P75 described as (P25; P75) for numerical data, in accordance with data distribution. The normality of data distribution was previously assessed with the Shapiro-Wilk test. The comparisons of DFM pressure parameters between execution modes (thumb vs. index finger) were performed using the Mann-Whitney test, once these variables did not present a normal distribution. The influence of the DFM pressure sequence on the time to the onset of analgesia was tested using the Kruskal-Wallis test. The comparison of the time to the onset of analgesia in each DFM pressure was tested using the Wilcoxon test. All statistical analyses were conducted considering $\alpha=0.05$. Analyses were performed with IBM ${ }^{\circledR}$ SPSS $^{\circledR}$ Statistics version 24.0 (IBM Corp, Armonk, NY, USA).

\section{Results}

\subsection{Characterization of the Pressures Applied during DFM (Study 1)}

Most of the 40 physiotherapists were female and worked in private practice (Table 1). Table 1 summarizes the participants' personal and professional characteristics.

Table 1. Personal and professional characteristics of the sample.

\begin{tabular}{|c|c|c|}
\hline & \multicolumn{2}{|c|}{ Final Sample } \\
\hline & $\mathbf{n}$ & $(\%)$ \\
\hline \multicolumn{3}{|l|}{ Sex } \\
\hline Female & 29 & 72.5 \\
\hline Male & 11 & 27.5 \\
\hline \multicolumn{3}{|l|}{ Academic degree } \\
\hline Physiotherapy degree & 34 & 85.0 \\
\hline Master degree & 6 & 15.0 \\
\hline \multicolumn{3}{|l|}{ Workplace } \\
\hline Public hospital & 2 & 5.0 \\
\hline Private hospital & 1 & 2.5 \\
\hline $\begin{array}{l}\text { Private practice, national } \\
\text { health service }\end{array}$ & 28 & 70.0 \\
\hline \multirow[t]{2}{*}{ Private practice, others } & 9 & 22.5 \\
\hline & \multicolumn{2}{|c|}{ Mean (SD) } \\
\hline Age (years) & \multicolumn{2}{|c|}{$30.5(6.10)$} \\
\hline Weight (kg) & \multicolumn{2}{|c|}{$63.6(9.90)$} \\
\hline Height $(\mathrm{cm})$ & \multicolumn{2}{|c|}{$168.7(7.24)$} \\
\hline \multirow[t]{2}{*}{ BMI $\left(\mathrm{kg} / \mathrm{m}^{2}\right)$} & \multicolumn{2}{|c|}{$22.3(3.02)$} \\
\hline & \multicolumn{2}{|c|}{ Median (percentile 25 (P25); percentile 75 (P75)) } \\
\hline Clinical experience (years) & \multicolumn{2}{|c|}{$7.0(1.00 ; 10.00)$} \\
\hline Work intensity (hour per week) & \multicolumn{2}{|c|}{$40.0(30.00 ; 40.00)$} \\
\hline $\begin{array}{l}\text { Number of patients treated ( } \mathrm{N} \text { per } \\
\text { hour) }\end{array}$ & \multicolumn{2}{|c|}{$4.0(3.00 ; 4.75)$} \\
\hline
\end{tabular}

The results showed a wide variation (Figure 3 ) on the pressures performed by the physiotherapists (mean pressure: $2.3 \mathrm{~kg} / \mathrm{cm}^{2}$ (P25: $1.02 \mathrm{~kg} / \mathrm{cm}^{2}$; P75: $4.16 \mathrm{~kg} / \mathrm{cm}^{2}$ ), median pressure: $2.1 \mathrm{~kg} / \mathrm{cm}^{2}($ P25: $\left.0.92 \mathrm{~kg} / \mathrm{cm}^{2} ; \mathrm{P} 75: 4.05 \mathrm{~kg} / \mathrm{cm}^{2}\right)$, minimum pressure: $0.7 \mathrm{~kg} / \mathrm{cm}^{2}\left(\mathrm{P} 25: 0.49 \mathrm{~kg} / \mathrm{cm}^{2} ; \mathrm{P} 75: 1.49 \mathrm{~kg} / \mathrm{cm}^{2}\right)$, maximum pressure: $\left.5.4 \mathrm{~kg} / \mathrm{cm}^{2}\left(\mathrm{P} 25: 2.56 \mathrm{~kg} / \mathrm{cm}^{2} ; \mathrm{P} 75: 9.40 \mathrm{~kg} / \mathrm{cm}^{2}\right)\right)$ and a moderate oscillation over time within the physiotherapists' executions (SD: $0.97 \mathrm{~kg} / \mathrm{cm}^{2}$ (P25: $0.38 \mathrm{~kg} / \mathrm{cm}^{2} ;$ P75: $\left.1.83 \mathrm{~kg} / \mathrm{cm}^{2}\right)$ ). The median time of the DFM executions was $206.5 \mathrm{~s}$ (P25: $170.0 \mathrm{~s}$; P75: $349.25 \mathrm{~s}$ ). 


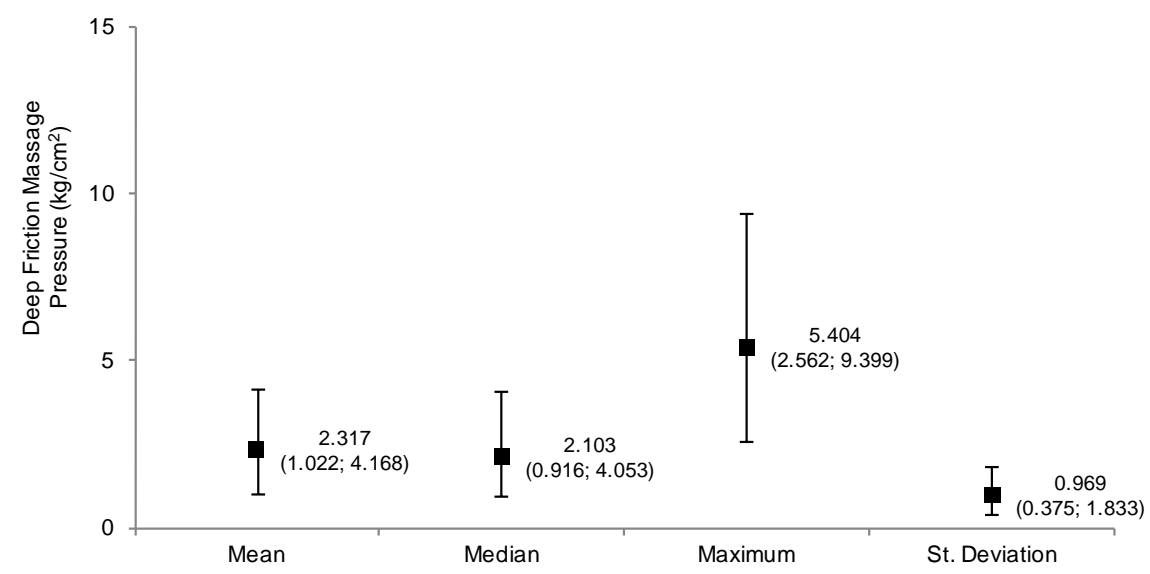

Figure 3. Median (P25; P75) of deep friction massage pressure parameters.

\subsection{Effects of Different DFM Pressures on the Time to the Onsite of Analgesia (Study 2)}

This study comprised 30 healthy subjects, most of which were female ( $n=21,70.0 \%$ of the sample). The mean age $( \pm \mathrm{SD})$ of the participants was $21.8 \pm 1.55$ years old, their mean weight was $65.1 \pm 8.01 \mathrm{~kg}$, their mean height was $1.7 \pm 0.08 \mathrm{~m}$, and their mean BMI was $23.3 \pm 2.02 \mathrm{~kg} / \mathrm{cm}^{2}$.

The time to the onset of analgesia in each DFM pressure is presented in Figure 4. The results showed an inverse dose-response relationship between the DFM pressure and the time to the onset of analgesia, i.e., when the DFM pressure increased the time to the onset of analgesia significantly decreased (DFM pressure: $1 \mathrm{~kg} / \mathrm{cm}^{2}$, time to the onset of analgesia: $84.5 \mathrm{~s} \mathrm{(P25:} 67.00 \mathrm{~s} ;$ P75: $113.50 \mathrm{~s}$ ); DFM pressure: $2.3 \mathrm{~kg} / \mathrm{cm}^{2}$, time to the onset of analgesia: $73.5 \mathrm{~s} \mathrm{(P25:} 59.00 \mathrm{~s}$; P75: $87.25 \mathrm{~s}$ ); DFM pressure: $4.2 \mathrm{~kg} / \mathrm{cm}^{2}$, time to the onset of analgesia: $54.0 \mathrm{~s}$ (P25: $37.75 \mathrm{~s} ;$ P75: $\left.\left.62.00 \mathrm{~s}\right)\right)(p \leq 0.001)$, with the difference in the time to reach analgesia between the lowest and the highest pressures of $30 \mathrm{~s}$ applied.

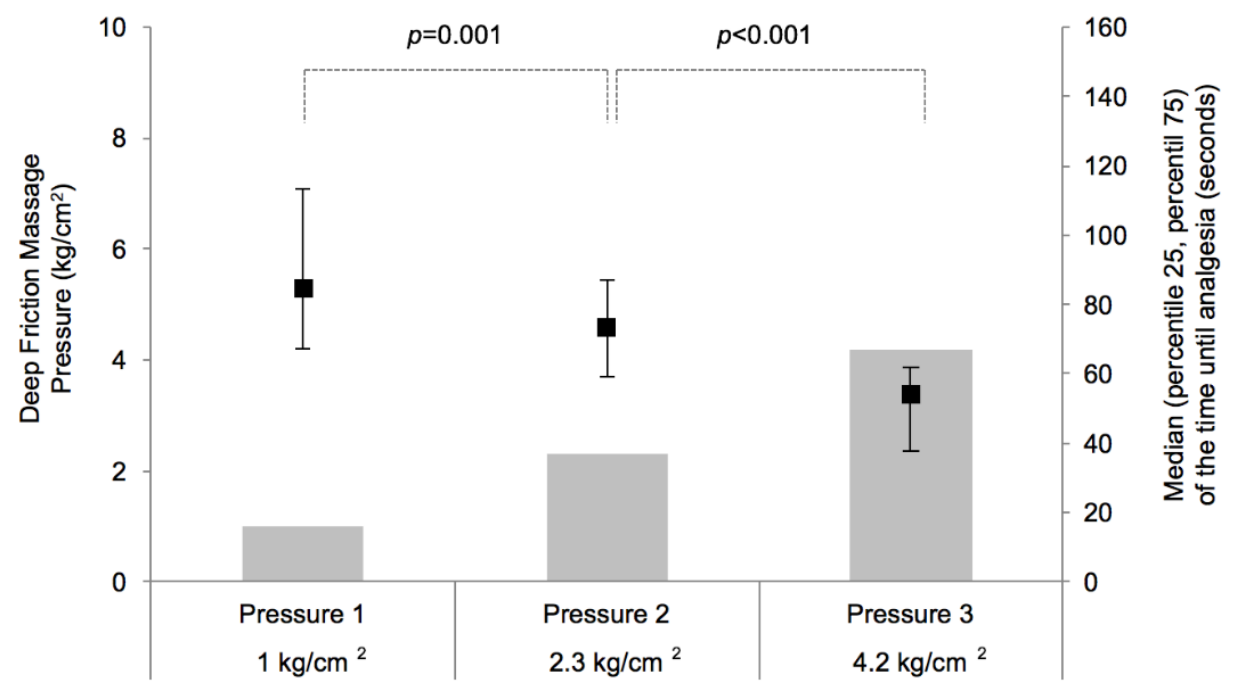

Figure 4. Deep friction massage pressure and the corresponding median (P25; P75) of the time until analgesia.

In order to manage the cumulative effect, the DFM pressures were applied in a randomized sequence. No statistically significant differences were found in the time to the onset of analgesia according to the pressure sequence (all $p>0.05$ ). 


\section{Discussion}

The aim of the present study was to characterize the pressures applied during DFM and to determine if a dose-response relationship existed between the pressure applied during DFM and the time to the onset of analgesia in an asymptomatic patellar tendon. Our results indicated that the mean pressure used by the physiotherapists during DFM was $2.3 \mathrm{~kg} / \mathrm{cm}^{2}\left(\mathrm{P} 25: 1.02 \mathrm{~kg} / \mathrm{cm}^{2} ; \mathrm{P} 75: 4.16 \mathrm{~kg} / \mathrm{cm}^{2}\right)$ and the higher the pressure of DFM the shorter the time to the onset of analgesia. Nonetheless, the difference between the lowest and the highest pressures on the time to reach analgesia was $30 \mathrm{~s}$.

To our best knowledge, this study is the first to quantify and analyze the intensity of the manual pressures applied by physiotherapists during the DFM application. The literature regarding DFM only described the pressures in a qualitative and subjective way as sufficient and constant [11,12]; this is reflected in the results of study 1 , which showed a wide variation on the pressures performed by the physiotherapists. Previous studies have shown that the intensity of the applied pressure has a directly proportional increase in the response of the recruitment and activation of fibroblasts [22,23]. The pressures described by those authors ranged between 5.1 and $15.3 \mathrm{~kg} / \mathrm{cm}^{2}$, which were much higher than those observed in our study. However, these studies only refer to morphological and histological effects, and the technique was applied longitudinally to the tendinous fibers with an instrument, i.e., the technique was not manual. Furthermore, it should be taken into account that these studies were carried out in animal models [22,23]. Regarding the influence of the application of different pressures on the time to the onset of analgesia (study 2), our results showed that a higher pressure of DFM led to a decrease in the time to the onset of analgesia, which may reflect a faster response of the presynaptic modulation mechanisms. Thus, a higher intensity of the mechanical stimulus (DFM pressure) will lead to the higher and faster activation of low-threshold $A-\alpha$ and $A-\beta$ fibers that inhibit the nociceptive input from $A-\delta$ and $C$ afferent fibers, which are responsible for nociceptive conduction at the dorsal horn of the spinal cord $[4,5,10,13-15,28,29]$.

The pressure performed during the DFM execution may act as a noxious stimulus, often called counterirritant, which is used as a conditioning stimulus to induce a reduction in the perception of conditioned pain modulation $[19,30]$. This mechanism induces analgesia through descending pain modulatory systems, wherein neurotransmitters like serotonin and endogenous opioids have been shown to modulate nociceptive circuits and pain outputs by acting on structures such as the rostral ventromedial medulla and periaqueductal grey (PAG). PAG is a crucial center for the endogenous analgesic system, where the autonomic and somatic responses to a nociceptive stimulus are integrated; moreover, it coordinates the descending activity of noradrenergic and serotoninergic systems that suppress the nociception between the dorsal horn and the spinal cord $[4,5,10,11,16,18,19,31]$. Notwithstanding, the present study used a sample of asymptomatic individuals, and it has been suggested that in conditions of "no pain" the descending noradrenergic system that originates in Locus Coeruleus has little influence, playing a minor role in basal pain sensitivity $[17,32]$. However, the reader should take into account the fact that the highest pressure only reduced the time to the onset of analgesia by $30 \mathrm{~s}$ (comparison between the lowest and the highest pressures), which raises the question about the clinical relevance of such a difference.

Some limitations should be acknowledged. First, it is important to point out that both studies were performed in asymptomatic individuals, which may interfere not only with the pressures applied by the physiotherapists (study 1) but also interfere with the pain modulation mechanisms (study 2). However, since it was not our objective to study and draw any conclusions about the mechanisms underlying DFM effects on pain, further considerations about the specific underlying mechanisms cannot be made. We also acknowledge that once study 1 was conducted in the laboratory, this could have conditioned the physiotherapists' performance during DFM. Notwithstanding, the conditions related to personal adjustments regarding the position of the physiotherapist and the hand position chosen were not imposed on the participant, so they performed the technique as in real contexts.

Future studies assessing the long-term effects of DFM in clinical populations should take these results into account by providing a tool to deliver a standardize pressure during the DFM application. 
Thus, it is important to assess whether the manual pressure is necessary to develop the effects intended and attributed to the technique (morphological, histological, and functional) [11,12], determining if different pressures influence clinical outcomes.

\section{Conclusions}

The present study was the first to objectively document the mean pressure applied by the physiotherapists during the DFM application, which was $2.3 \mathrm{~kg} / \mathrm{cm}^{2}\left(\mathrm{P} 25: 1.02 \mathrm{~kg} / \mathrm{cm}^{2} ; \mathrm{P} 75: 4.16 \mathrm{~kg} / \mathrm{cm}^{2}\right)$. A wide variation on the pressures performed by the physiotherapists was found as well as a moderate oscillation over time within the physiotherapists' executions. Moreover, our results have shown that higher pressures of DFM resulted in shorter times to the onset of analgesia.

Author Contributions: Conceptualization, P.C., F.P., J.A.D., and F.R.; methodology, P.C., M.P., F.P., and F.R.; software, F.P.; investigation, P.C., M.P., and F.P.; writing of the original draft preparation, P.C., M.P., D.S., and F.R.; writing of review and editing, P.C., J.A.D., and F.R.; visualization, M.P., F.P., and D.S. All authors have read and agreed to the published version of the manuscript.

Funding: This research received no external funding.

Acknowledgments: CIAFEL is a research unit supported by the Portuguese Foundation for Science and Technology (reference: UID/DTP/00617/2020). iBiMED is a research unit supported by the Portuguese Foundation for Science and Technology (reference: UID/BIM/04501/2020) and FEDER/Compete2020 funds.

Conflicts of Interest: The authors declare no conflicts of interest.

\section{References}

1. Brosseau, L.; Casimiro, L.; Milne, S.; Welch, V.; Shea, B.; Tugwell, P.; Wells, G.A. Deep Transverse Friction Massage for Treating Tendinitis. Cochrane Database Syst. Rev. 2002, 4, CD003528.

2. Childress, M.A.; Beutler, A. Management of Chronic Tendon Injuries. Am. Fam. Phys. 2013, 87, 486-490.

3. Cook, J.L.; Purdam, C.R. Is Tendon Pathology a Continuum? A Pathology Model to Explain the Clinical Presentation of Load-Induced Tendinopathy. Br. J. Sports Med. 2009, 43, 409-416. [CrossRef] [PubMed]

4. De Bruijn, R. Deep Transverse Friction: Its Analgesic Effect. Int. J. Sports Med. 1984, 5, 35-36. [CrossRef]

5. Goats, G.C. Massage-the Scientific Basis of an Ancient Art: Part 2. Physiological and Therapeutic Effects. Br. J. Sports Med. 1994, 28, 153-156. [CrossRef] [PubMed]

6. Leadbetter, J.D. The Effect of Therapeutic Modalities on Tendinopathy. In Tendon Injuries: Basic Science and Clinical Medicine; Maffulli, N., Wayne, P.R., Leadbetter, B., Eds.; Springer: Berlin/Heidelberg, Germany, 2005; Volume 9.

7. Loppini, M.; Maffulli, N. Conservative Management of Tendinopathy: An Evidence-Based Approach. MuscleLigaments Tendons J. 2011, 1, 134-137.

8. Maffulli, N.; Longo, U.G.; Denaro, V. Novel Approaches for the Management of Tendinopathy. J. Bone Jt. Surg. Am. 2010, 92, 2604-2613.

9. Rees, J.D.; Maffulli, N.; Cook, J. Management of Tendinopathy. Am. J. Sports Med. 2009, 37, $1855-1867$. [CrossRef]

10. Stasinopoulos, D.; Johnson, M.I. Cyriax Physiotherapy for Tennis Elbow/Lateral Epicondylitis. Br. J. Sports Med. 2004, 38, 675-677. [CrossRef]

11. Atkins, E.; Kerr, J.; Goodlad, E. A Practical Approach to Orthopaedic Medicine: Assessment, Diagnosis, Treatment, 3rd ed.; Churchill Livingstone: Edinburgh, UK, 2010.

12. Chamberlain, G.J. Cyriax's Friction Massage: A Review. J. Orthop. Sports Phys. Ther. 1982, 4, 16-22. [CrossRef]

13. Gregory, M.A.; Deane, M.N.; Mars, M. Ultrastructural Changes in Untraumatised Rabbit Skeletal Muscle Treated with Deep Transverse Friction. Physiotherapy 2003, 89, 408-416. [CrossRef]

14. Hassan, S.M.; Hafez, A.R.; Seif, H.E.; Kachanathu, S.J. The Effect of Deep Friction Massage Versus Stretching of Wrist Extensor Muscles in the Treatment of Patients with Tennis Elbow. Open J. Ther. Rehabil. 2016, 4, 48-54. [CrossRef] 
15. Viswas, R.; Ramachandran, R.; Anantkumar, P.K. Comparison of Effectiveness of Supervised Exercise Program and Cyriax Physiotherapy in Patients with Tennis Elbow (Lateral Epicondylitis): A Randomized Clinical Trial. Sci. World J. 2012, 2012, 939645. [CrossRef] [PubMed]

16. Bialosky, J.E.; Bishop, M.D.; Price, D.D.; Robinson, M.E.; George, S.Z. The Mechanisms of Manual Therapy in the Treatment of Musculoskeletal Pain: A Comprehensive Model. Man. Ther. 2009, 14, 531-538. [CrossRef] [PubMed]

17. Meritxell, L.-T.; Borges, G.; Neto, F.; Mico, J.A.; Berrocoso, E. Noradrenergic Locus Coeruleus Pathways in Pain Modulation. Neuroscience 2016, 338, 93-113.

18. Pud, D.; Granovsky, Y.; Yarnitsky, D. The Methodology of Experimentally Induced Diffuse Noxious Inhibitory Control (Dnic)-Like Effect in Humans. Pain 2009, 144, 16-19. [CrossRef]

19. Andrew, V.; Ryan, D.; Bruhns, P. The Role of Descending Modulation in Manual Therapy and Its Analgesic Implications: A Narrative Review. Pain Res. Treat. 2015, 2015, 1-11.

20. Cyriax, J.H.; Cyriax, P.J. Cyriax's Illustrated Manual of Orthopaedic Medicine, 2nd; Butterworth-Heinemann: Oxford, UK, 1993.

21. Loew, L.M.; Brosseau, L.; Tugwell, P.; Wells, G.A.; Welch, V.; Shea, B.; Poitras, S.; De Angelis, G.; Rahman, P. Deep Transverse Friction Massage for Treating Lateral Elbow or Lateral Knee Tendinitis. Cochrane Database Syst. Rev. 2014, 11, CD003528. [CrossRef] [PubMed]

22. Davidson, C.J.; Ganion, L.R.; Gehlsen, G.M.; Verhoestra, B.; Roepke, J.E.; Sevier, T.L. Rat Tendon Morphologic and Functional Changes Resulting from Soft Tissue Mobilization. Med. Sci. Sports Exerc. 1997, 29, 313-319. [CrossRef]

23. Gehlsen, G.M.; LGanion, R.; Helfst, R. Fibroblast Responses to Variation in Soft Tissue Mobilization Pressure. Med. Sci. Sports Exerc. 1999, 31, 531-535. [CrossRef]

24. Sterns Mary, L. Studies on the Development of Connective Tissue in Transparent Chambers in the Rabbit's Ear. II. Am. J. Anat. 1940, 67, 55-97. [CrossRef]

25. Paula, C.; Simões, D.; Paço, M.; Pinho, F.; Duarte, J.A.; Ribeiro, F. Cyriax's Deep Friction Massage Application Parameters: Evidence from a Cross-Sectional Study with Physiotherapists. Musculoskelet. Sci. Pract. 2017, 14, 92-97.

26. Joseph, M.F.; Taft, K.; Moskwa, M.; Denegar, C.R. Deep Friction Massage to Treat Tendinopathy: A Systematic Review of a Classic Treatment in the Face of a New Paradigm of Understanding. J. Sport Rehabil. 2012, 21, 343-353. [CrossRef] [PubMed]

27. Prabhakar, A.J.; Kage, V.; Anap, D. Effectiveness of Cyriax Physiotherapy in Subjects with Tennis Elbow. J. Nov. Physiother. 2013, 3. [CrossRef]

28. Blackwood, J.; Ghazi, F. Can the Addition of Transverse Friction Massage to an Exercise Programme in Treatment of Infrapatellar Tendinopathy Reduce Pain and Improve Function? A Pilot Study. Int. Musculoskelet. Med. 2012, 34, 108-114. [CrossRef]

29. Goats, G.C. Massage-the Scientific Basis of an Ancient Art: Part 1. The Techniques. Br. J. Sports Med. 1994, 28, 149-152. [CrossRef]

30. Yarnitsky, D. Conditioned Pain Modulation (the Diffuse Noxious Inhibitory Control-Like Effect): Its Relevance for Acute and Chronic Pain States. Curr. Opin. Anesthesiol. 2010, 23, 611-615. [CrossRef]

31. Wright, A.; Sluka, K.A. Nonpharmacological Treatments for Musculoskeletal Pain. Clin. J. Pain 2001, 17, 33-46. [CrossRef]

32. Antti, P. The Noradrenergic Pain Regulation System: A Potential Target for Pain Therapy. Eur. J. Pharmacol. $2013,716,2-7$.

(C) 2020 by the authors. Licensee MDPI, Basel, Switzerland. This article is an open access article distributed under the terms and conditions of the Creative Commons Attribution (CC BY) license (http://creativecommons.org/licenses/by/4.0/). 